\title{
Breastfeeding Practices as Observed in Those Attending a Teaching Hospital for Perinatal Care
}

\author{
Anyanwu $\mathrm{OU}^{1}$, Ezeonu $\mathrm{CT}^{2}$, Ezeanosike $\mathrm{OB}^{3}$, Okike $\mathrm{CO}^{4}$
}

\begin{abstract}
Introduction: The promotion and support of breastfeeding is a global priority with benefits for maternal and infant health, especially in low-income and middle-income countries where the relevance for child survival is undisputed. Timely initiation of breastfeeding within one hour of birth, exclusive breast feeding for six months with continued breastfeeding till 2 years and beyond are important aspects of breast feeding for child survival. The objective of the study was to describe the practice and perception of breast feeding amongst mothers at the post natal wards of the Federal Teaching Hospital, Abakaliki. Materials and Methods: This study was a questionnaire based cross sectional view of breastfeeding practices of mothers who received perinatal care at the Federal Teaching Hospital Abakaliki, Ebonyi, South Eastern Nigeria. Results: $16.1 \%$ initiated breast feeding within one hour, while others initiated later for reasons like poor lactation (19.6\%); too tired (15.4\%); felt dirty after delivery (5.3\%) and caesarean section. Exclusive breastfeeding was not the intention of $30.8 \%$ for reasons like, too demanding (15.4\%); cannot satisfy baby (38.6\%); spouse and relations would not accept (26.5\%); Work/School schedule would not permit (13.6\%). Mode of delivery and socioeconomic class were significantly associated with time of initiation. Neither maternal age nor parity significantly influenced the overall practice of breastfeeding. Conclusion: Few mothers practice correct breastfeeding in this tertiary health institution suggesting that more work to improve the knowledge and attitudes of mothers is required starting from the antenatal period.
\end{abstract}

Key words: Breastfeeding, Initiation, Mother, Practices

\section{Introduction}

D reastfeeding is the process of providing optimal nutrition for D the growth and development of the infant ${ }^{1}$. It is an important aspect of child survival as it provides adequate nutrition at the right conditions for the human infant ${ }^{1}$. Correct breastfeeding practises involves timely initiation of breastfeeding, exclusive breastfeeding for the first six months and continued breastfeeding with appropriate complementary feeds till two years and beyond ${ }^{2}$. Timely initiation of breastfeeding is defined as putting the new born to the breast within one hour of birth. It is easy, cost effective and has been shown to
'Dr. Anyanwu OU, MBBS, MNPMC, MWACP Senior Registrar, Federal Teaching Hospital Abakaliki, Nigeria, ${ }^{2}$ Ezeonu CT, MBBS, FNPMC, Senior Lecturer/Consultant Community Paediatricians. ${ }^{3}$ Ezeanosike OB Lecturer/Consultant Neonatologist MBBS, FWACP, ${ }^{4}$ Okike CO, Lecturer/Consultant Paediatrics Haematologist MBBS, FWACP.

Address for correspondence:

Dr. Anyanwu OU

E-mail: onyinyeanyanwugc@gmail.com

\section{How to cite}

Anyanwu OU, Ezeonu CT, Ezeanosike OB, Okike CO. Breastfeeding Practices as Observed in Those Attending a Teaching Hospital for Perinatal Care. J Nepal Paediatr Soc 2014;34(2):90-95.

doi: http://dx.doi.org/10.3126/jnps.v34i2.8788

This work is licensed under a Creative Commons Attribution 3.0 License.

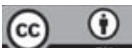

be a successful intervention in saving the life and health of the new born. Exclusive breastfeeding means that the infant receives only breast milk and no other solids or liquids, including water, with the exception of drops or syrups consisting of vitamin or mineral supplements or medicines ${ }^{2}$.

The promotion and support of breastfeeding is a priority globally especially in low and middle-income countries where its relevance for child survival is undisputed due to the benefits for maternal and infant health ${ }^{3}$. Correct breastfeeding practices are important aspects of interventions for child survival ${ }^{4,5}$. 
An estimated four million new-borns die annually, $98 \%$ of which are from low and middle income countries ${ }^{6}$. Most of these newborn deaths are attributable to preventable causes especially infections. Lauer et $\mathrm{al}^{7}$ estimated that as many as 1.45 million lives are lost in the world over due to suboptimal breast-feeding in developing countries. Similarly, Edmond et $\mathrm{al}^{8}$ in Ghana showed a protective relationship between early initiation of breastfeeding and neonatal mortality risk. They reported that ensuring initiation of breastfeeding within 1 hour could cut $22 \%$ of all neonatal mortality and that neonatal mortality increased markedly as delay in initiation increased. It is for these perceived benefits that the Baby Friendly Hospital Initiative (BFHI) a UNICEF driven project was introduces into Nigeria amongst other countries and precisely into the tertiary hospital in Abakaliki about nine years ago. However the donor agency has since withdrawn its services. What has become of breastfeeding in our country and Abakaliki?

A mother's decision and ability to practice correct breastfeeding starting from initiating breastfeeding within the first hour is influenced by several factors. Such factors include misconceptions that the mother may not be able to produce adequate amounts of milk soon after birth, lack of support from the health care system, societal norms, values and beliefs such as the belief that colostrum should be thrown away as it is witches milk ${ }^{9}$. Others are family or spouses' attitude to breastfeeding, 'fixed' hospital routines such as starting with formula or glucose water after birth (pre lacteal feeds), which directly contributes to failure to initiate breastfeeding within one hour ${ }^{9}$. Bartington et al $^{10}$ reported other factors such as a planned pregnancy, attendance at antenatal classes, vaginal delivery, being accompanied at delivery, and a post-partum hospital stay of $>24 \mathrm{hr}$ which were independently associated with timely initiation of breast feeding in their study. In another study, Ayton et al ${ }^{11}$ reported that preterm birth is predictive of breastfeeding failure, with late preterm infants at greater risk of not initiating breastfeeding and/or exclusively breastfeeding at hospital discharge. Certain factors identified by Agbo et al ${ }^{12}$ would serve as motivators to the working mother to practice EBF; these were good family support and longer maternity leave (25.5\%). Others include early closure from work (17.0\%), prolongation of the maternity leave period and provision of crèches at places of work (10.6\%). It is on this background that this study was aimed at describing the practice of breastfeeding of mothers starting at timing of initiation, and their perception, at the labour and postnatal wards of the Federal Teaching Hospital, Abakaliki.

\section{Materials and Methods}

A cross sectional and descriptive study sited at the labour and postnatal wards of Federal Teaching Hospital Abakaliki (FETHA), Ebonyi State, a designated baby friendly tertiary institution in Ebonyi State. The Obstetrics and gynaecology department of FETHA is a busy area with a total bed capacity of about 150 which includes the gynaecologic ward, the antenatal wards, the labour ward and the postnatal ward. The labour and postnatal wards have together 55 beds. On the average, 126 deliveries occur monthly.

Data collection was done between April and June 2012. Consecutive convenient sample of mothers were the participants. Included in the study were well-mothers of live full-term, well new-borns who willingly participated. Mothers who were unstable and mothers of sick new-borns were excluded. A structured questionnaire was used to obtain the subjects age, parity, highest level of education and occupation as well as her spouses' education and occupation. Also contained in the questionnaire were questions obtaining the time after birth, when the new born was initiated to breastfeeding, reasons for untimely initiation and intent to breastfeed exclusively for 6 months. Subjects who could not read had the questions read to them in their local language and their responses were recorded. Direct observation was also used since the subjects were still on admission.

Subjects were stratified into socioeconomic strata by combining the scores given for their education to that given for their spouses' occupation as used previously by Olusanya et $\mathrm{al}^{13}$.

The statistical package for the social sciences (SPSS) version 17 and Epi Info version 12.1 were used for data analysis. Descriptive statistics were used to summarize the data. Cross tabulations were done and comparisons made of the parity of mother, socioeconomic class, age of mother, mode of delivery to the time of initiation of breastfeeding. Pearson Chisquare test and Fisher's Exact test where required were used to test the comparisons. Confidence interval was set at $95 \%$ and significant $p$-value of $<0.05$ was accepted. Ethical approval for the study was obtained from the FETHA research and ethics committee.

\section{Results}

160 mothers who fulfilled the inclusion and exclusion criteria were recruited and were given questionnaires. However 17 questionnaires were incompletely filled or had vague responses hence 
143 was analysed. Majority (74.8\%) of mothers were 30 years and below, belonged to the Igbo tribe (92.3\%), were Christians (94.4\%), and of the middle socioeconomic class (39.2\%). Their mean age was 28 \pm 3.4 years, with a range of $19-39$ years. $69.2 \%$ had unassisted vaginal deliveries, $25.2 \%$ delivered through caesarean section while $5.6 \%$ had assisted vaginal deliver. Primiparous mothers constituted $29.4 \%$ of participants, while $16.1 \%$ were grand multiparous women. Their new-borns were more males (55.2\%) than females. Table 1 shows the socio demographic characteristics of the respondents.

Timely initiation of breastfeeding, that is in $<1$ hour, was practiced by $16.1 \%$ of subjects, while $43.4 \%$ initiated between $>1-6$ hours, $16.8 \%$ between $>6-12$ hours, $5 \%$ between $>12-18$ hours, $4.6 \%$ between $18-24$ hours and $>14.7 \%$ initiating after 24 hours. (Table 2)

The mean time for initiation of breastfeeding was 3.12 hours for those who delivered vaginally, 5.02 hours for assisted vaginal delivery and 20.6 hours for those delivering by caesarean session. Up to $28.2 \%$ of respondents expressed their first breast milk and discarded it while $19.1 \%$ gave pre-lacteal feeds consisting of glucose water and plain water in place of breast milk. Reasons for not initiating within the first hour was having had a caesarean section (20.3\%), not seeing milk coming out of their breast (19.6\%), and being too tired to breastfeed immediately (16.1\%).
Other reasons for untimely initiation of breastfeeding were that the respondent was still being cleaned up in the labour room (15.4\%), 6.3\% felt baby was too tired to suckle, and another $6.3 \%$ felt they were too dirty to breastfeed immediately. Those who discarded their colostrum did so because they felt it was not good for the new born hence most gave water or glucose water instead (Table 3).

Exclusive breastfeeding for 6 months was not the intention for $30.8 \%$. Misconceptions that baby would not gain weight on breast milk alone was the major reason (38.6\%), for $20.5 \%$ their reason was that their spouses and/or relations would not permit EBF, 15.9\% felt it was too stressful, $13.6 \%$ was attributable to work/school schedule while the rest gave no reason.

Only $9.1 \%$ intended to continue breastfeeding till their baby was 2 years, the rest intending to stop breast feeding on or around their first birthday. The reasons for their choices were, anticipation of another pregnancy (29.4\%), previous practice with older children (29.4\%), the health of the baby $(21.0 \%)$, other people's opinion (13.3\%), and the right practice (7.0\%).

Comparing timing of initiation with maternal age, parity, and sex of the new born showed no statistical significance, $(p>0.05)$ however, mode of delivery (TABLE 4) and socioeconomic class (TABLE 5) were found to significantly affect initiation of breastfeeding time $(p<0.05)$.

Table 1: Socio demographic characteristics of respondents.

\begin{tabular}{|l|c|c|}
\hline Socio-demographic Variables & Category & Frequency (\%) \\
\hline \multirow{2}{*}{ Age } & $<21$ years & $11(7.7)$ \\
& $21-25$ years & $15(10.5)$ \\
& $26-30$ years & $81(56.6)$ \\
& $31-35$ years & $23(16.1)$ \\
Religion & $>35$ years & $13(9.1)$ \\
\hline & Christianity & $135(94.4)$ \\
Ethnicity & Islamic & $7(4.9)$ \\
& Others & $1(0.7)$ \\
\hline \multirow{3}{*}{ Socioeconomic Class } & Igbo & $132(92.3)$ \\
& Hausa & $6(4.2)$ \\
& Yoruba & $2(1.4)$ \\
Sex of Newborn & Others & $3(2.1)$ \\
\hline & Lower & $37(25.9)$ \\
Mode of Delivery & Middle & $56(39.2)$ \\
& Upper & $50(35.0)$ \\
\hline & Female & $64(44.8)$ \\
& Unassisted vaginal & $79(55.2)$ \\
\hline
\end{tabular}


Table 2: Showing the time of initiation of breastfeeding

\begin{tabular}{|c|c|}
\hline How many hours after birth did you initiate breastfeeding & Frequency (\%) \\
\hline Within 1 hour & $23(16.1)$ \\
\hline$>1-6$ hours & $62(43.4)$ \\
\hline$>6-12$ hours & $24(16.8)$ \\
\hline$>12-18$ hours & $7(5.0)$ \\
\hline$>18-24$ hours & $6(4.6)$ \\
\hline$>24$ hours & $21(14.7)$ \\
\hline Total & $143(100.0)$ \\
\hline
\end{tabular}

Table 3: Showing Reasons for Late Initiation of Breast feeding.

\begin{tabular}{|l|c|}
\hline Reasons for late initiation of breast feeding & Frequency (\%) \\
\hline Caesarean session & $29(20.3)$ \\
\hline Prolonged labour room routines and stay & $22(15.4)$ \\
\hline No milk seen letting down from breast & $28(19.6)$ \\
\hline Too tired after labour & $23(16.1)$ \\
\hline Felt too dirty to breastfeeding after labour & $9(6.3)$ \\
\hline Felt baby was too tired & $9(6.3)$ \\
\hline
\end{tabular}

Table 4: Showing cross tabulation of time of initiation and mode of delivery $(p<0.05)$.

\begin{tabular}{|c|c|c|c|c|c|}
\hline & \multicolumn{5}{|c|}{ Time of initiation of breastfeeding } \\
\hline Mode of delivery(n) & $\begin{array}{c}\text { Within 1 hour } \\
\text { Freq (\%) }\end{array}$ & $\begin{array}{c}\mathbf{> 1 - 6} \text { hours } \\
\text { Freq (\%) }\end{array}$ & $\begin{array}{c}\mathbf{> 6 - 1 2} \text { hours } \\
\text { Freq (\%) }\end{array}$ & $\begin{array}{c}\mathbf{> 1 2 - 2 4} \text { hours } \\
\text { Freq (\%) }\end{array}$ & $\begin{array}{c}\mathbf{> 2 4} \text { hours } \\
\text { Freq (\%) }\end{array}$ \\
\hline Unassisted vaginal(99) & $22(22.2)$ & $54(54.5)$ & $18(18.2)$ & $1(1.0)$ & $4(4.0)$ \\
\hline Caesarean session(36) & $0(0.0)$ & $5(13.9)$ & $3(8.3)$ & $11(30.6)$ & $17(47.2)$ \\
\hline Assisted vaginal (8) & $1(12.5)$ & $3(37.5)$ & $3(37.5)$ & $1(12.5)$ & $0(0.0)$ \\
\hline
\end{tabular}

Table 5: Showing cross-tabulation of time of initiation and socioeconomic class $(p<0.05)$.

\begin{tabular}{|c|c|c|c|c|c|}
\hline & \multicolumn{5}{|c|}{ Time Of Initiation Of Breastfeeding } \\
\hline $\begin{array}{c}\text { Socioeconomic } \\
\text { Class (N) }\end{array}$ & $\begin{array}{c}\text { Within 1 Hour } \\
\text { Freq (\%) }\end{array}$ & $\begin{array}{c}>1-6 \text { Hours } \\
\text { Freq (\%) }\end{array}$ & $\begin{array}{c}\text { >6-12 Hours } \\
\text { Freq (\%) }\end{array}$ & $\begin{array}{c}\text { >12-24 Hours } \\
\text { Freq(\%) }\end{array}$ & $\begin{array}{c}\text { >24 Hours } \\
\text { Freq (\%) }\end{array}$ \\
\hline Lower (37) & $2(5.4)$ & $13(35.1)$ & $6(16.2)$ & $7(18.9)$ & $9(24.3)$ \\
\hline Middle (56) & $10(17.9)$ & $26(46.4)$ & $9(16.1)$ & $5(8.9)$ & $6(10.7)$ \\
\hline Upper (50) & $11(22.0)$ & $23(46.0)$ & $9(18.0)$ & $1(2.0)$ & $6(12.0)$ \\
\hline
\end{tabular}

\section{Discussion}

Despite the World Health Organization (WHO), global infant and young child feeding guidelines which recommends that all new-borns should start breastfeeding immediately (within the first hour after delivery) with promotion for the feeding of colostrum, a low prevalence, $16.1 \%$, of timely initiation of breastfeeding was obtained in this study. This figure is lower than a previous Nigerian study ${ }^{12}$ where a prevalence of $61.7 \%$ was reported amongst female resident doctors but within the range of $16-54 \%$ reported in India ${ }^{9}$. Prevalence rates reported from studies carried out in other countries were remarkably higher ranging from $49.5 \%$ in Jordan to $72.7 \%$ amongst
385 mothers in a sub metropolitan city in western Nepal ${ }^{14-17}$. However, a more recent report ${ }^{18}$ adapted from the 2011 Nepal Demographic and Health survey (NDHS) reported a prevalence rate of $44.4 \%$ for timely initiation of breastfeeding amongst 3948 participants. The wide variation may be attributable to larger sample sizes as well as settings of the different studies. Current study has shown that a good number of mothers $(28.2 \%)$ still had misconceptions about colostrum calling for intense education of the general public and at antenatal clinics so that the practice of discarding colostrum can be stopped. The study has also shown that having a caesarean session was a major reason for late initiation of breastfeeding. However, it is worthy of note that participants whose delivery was vaginal 
had other reasons for late initiation of breastfeeding. Misconceptions such as the feeling that milk must be seen letting down before initiation or the feelings that the baby was too tired to suckle after the stress of labour were leading deterrents to timely initiation of breastfeeding. For other respondents, delayed initiation was attributed to delays within the delivery room showing how prolonged routine practices within the labour ward may interfere with the timing of breastfeeding initiation.

At the point of delivery, up to $30.8 \%$ had no intent of breastfeeding exclusively for the first 6months, majority attributing their decision to misconceptions that the new born would not gain weight $(38.6 \%)$ and to having poor family support (20.5\%). Only $9.1 \%$ wanted to breastfeed for 2 years with the majority $23 \%$ planning to stop breastfeeding at the first birthday. Anticipation of another pregnancy and previous practice being their most common deterrents to continued breastfeeding till 2 years. The length of breast feeding of a good number of mothers (13.3\%) were influenced by what other people say about breastfeeding hence the importance of further education of the society with respect to breastfeeding.

Current study further reiterates the need for continued education of the populace as well as support for antenatal care to improve breast feeding practices amongst women of child bearing age. Health facilities should embark on training and re-training of their health-workers to promote correct breastfeeding practices amongst their patients, the achievement of which may contribute to achieving WHO goal of correct breastfeeding practice.

The major limitation of this study is the fact that Exclusive breast feeding rate was estimated by asking the intent of respondents to practice of exclusive breastfeeding knowing that the actual number who would practice exclusive breastfeeding may differ from the number with the intent.

\section{Conclusion}

The rates of timely initiation of breastfeeding were undesirably low, and the practice of pre lacteal feeding existed even in a tertiary care hospital. Campaigns for improved knowledge have to be instituted to the society to deal with misconception if WHO standards of correct breast feeding must be met. Health workers must ensure skin-to-skin contact of infants and their mothers immediately after birth within 1 hour and routine labour ward practices made to take less time.
Acknowledgement: Nil

Funding: Nil

Conflict of Interest: None.

Permission from IRB: Yes.

\section{References}

1. Egbuonu I, Ojukwu JU. Infant feeding. In: Azubuike JC, Nkanginieme KEO, editors. Paediatrics and Child health in a tropical region. African educational services 2007;224-239.

2. World Health Organization, United Nations Children's Fund. Global strategy for infant and young child feeding. 2003.

3. Rafael PE. Evidence Based Breast-Feeding Promotion: The Baby-Friendly Hospital Initiative. J Nutr 2007;137(2):484-487.

4. Jones G, Steketee RW, Black RE, Bhutta AZ, Morris SS, Bellagio. Child Survival Study Group How many child deaths can we prevent this year? Lancet 2003;362:67-71.

5. WHO Collaborative Study Team on the Role of Breastfeeding on the Prevention of Infant Mortality. Effect of breastfeeding on infant and child mortality due to infectious diseases in less developed countries: a pooled analysis. Lancet 2000;355:451-5.

6. Lawn J, Cousens S, Zupan J. 4 million neonatal deaths: When? Where? Why? Lancet 2005;365:891-900.

7. Lauer JA, Betran AP, Barros AJ, de Onis M. Deaths and years of life lost due to suboptimal breastfeeding among children in the developing world: a global ecological risk assessment. Public Health Nutr 2006;9(6):673-85.

8. Edmond KM, Zandoh C, Quigley MA, AmengaEtego S, Owusu-Agyei S, Kirkwood BR. Delayed Breastfeeding Initiation Increases Risk of Neonatal Mortality. Pediatrics 2006;117:380-386.

9. Patel A, Banerjee A, Kaletwad A. Factors associated with prelacteal feeding and timely initiation of breastfeeding in hospital-delivered infants in India. J Hum Lact 2013;29(3).

10. Bartington S, Griffiths L J, Tate RA, et al. Are breastfeeding rates higher among mothers delivering in Baby Friendly accredited maternity units in the UK? Int J Epidemiol 2006; 35(5):11781186.

11. Ayton L, Hansen E, Quinn S, Nelson M. Factors associated with initiation and exclusive 
breastfeeding at hospital discharge: late preterm compared to 37 weeks gestation mother and infant cohort. Int Breastfeeding J 2012;7:16.

12. Agbo HA, Envuladu EA, Adams HS, Inalegwu E, Okoh E, Agba A, Zoakah Al. Barriers and facilitators to the practise of exclusive breastfeeding among working class mothers: Astudy of female resident doctora in tertiary health institutions in Plateau state. E3 J Med Res 2013; 2(1): 0112-0116.

13. Olusanya $\mathrm{O}$, Okpere EE, Ezimokhai M. The importance of social class in voluntary fertility control in a developing country. West Afr $\mathrm{J}$ Med 1985;4:252-5.

14. Khassawneh $\mathrm{M}$, Khader $\mathrm{Y}$, Amarin Z. Knowledge, attitude and practice of breastfeeding in the north of Jordan: a cross-sectional study. Int Breastfeeding J 2006, 1:17.
15. Oweis A, Tayem A, Froelicher ES: Breastfeeding practices among Jordanian women. Int J Nursing Prac 2009; 15:32-40.

16. Alemayehu T, Haidar J, Habte D: Determinants of exclusive breastfeeding practices in Ethiopia. Ethiop J Health Dev 2009, 23(1):12-18.

17. Chandrashekhar TS, Joshi HS, Binu VS: Breastfeeding initiation and determinants of exclusive breast-feeding: A questionnaire survey in an urban population of western Nepal. Pub Health Nutr 2007;10(2):192-9.

18. Ministry of Health and Population (MOPH). Nepal Demographic and Health Survey 2011. Kathmandu, Nepal: Ministry of Health and Population, New ERA, International, Calverton Maryland. 